Philippine Journal of Psychology, 2018, 51(1), 101-120

Copyright @ 2018 Psychological Association of the Philippines

\title{
Career and Talent Development Self-Efficacy of Filipino Students: The Role of Self-Compassion and Hope
}

\author{
Ma. Jenina N. Nalipay \\ Philippine Normal University \\ Maria Kristina S. Alfonso \\ Ateneo de Manila University
}

\begin{abstract}
The recent reforms in the Philippine educational system aim to develop lifelong learners who are competent in their chosen career and capable of contributing to society. Career and talent development self-efficacy is an enabling resource that could facilitate the realization of these goals. The present study examines a model of career and talent development self-efficacy predicted by self-compassion through hope in a sample of Filipino college students $(N=620)$. Results of structural equation modeling revealed that the model has good fit to the data, and that self-compassion has a significant indirect effect on career and talent development self-efficacy through hope. These findings highlight the importance of developing students' personal resources in order to maximize their skills and abilities in developing their talents and being successful in their chosen career.
\end{abstract}

Keywords: career and talent development self-efficacy, self-compassion, hope

Recent reforms in the Philippine educational system (i.e., Enhanced Basic Education Act of 2013, the implementation of the K to 12 Program) aim to prepare students for lifelong learning, enhance

Correspondence concerning this article can be addressed to Ma. Jenina N. Nalipay, Educational Policy Research and Development Center, Philippine Normal University, Taft Avenue, Manila, Philippines. Email: nalipay.mjn@pnu.edu.ph 
their competence for their chosen career paths, and promote positive changes to oneself and society. However, in order to fully realize these goals, developing students' personal resources may be as important as making changes in the curriculum. Indeed, positive education, which integrates positive psychological approaches to traditional education, acknowledges the importance of enhancing students' personal strengths and well-being above and beyond developing their academic skills and competencies in order to help them flourish (Norris, Williams, O'Connor, \& Robinson, 2013; Seligman, 2011). In connection with this, the present study examines the relationships of positive psychological constructs-self-compassion, hope, and career and talent development self-efficacy, which can contribute to the attainment of the aforementioned goals for Filipino learners.

\section{Career and Talent Development Self-Efficacy}

Self-efficacy is the belief that one is capable of coordinating his or her skills and abilities in order to achieve desired goals in a certain domain or circumstance, and that one can perform actions that can lead to the desired goals (Maddux, 2002). It is an enabling resource that provides people with skills that allow them to choose and attain the life goals they desire. Its view of individuals as active agents capable of initiating change in their own lives and that of others, and its focus on one's potentials and possibilities rather than limitations establish self-efficacy as a relevant construct in positive psychology (Maddux, 2002).

Self-efficacy is an important factor in career development, specifically in one's academic and career interests, choice, and performance, along with goals and outcomes expectations (Lent, Brown, \& Hacket, 2002). Self-efficacy is viewed as a dynamic set of self-beliefs regarding one's performance in specific domains that has complex interactions with personal, behavioral, and environmental factors, and is strongly influenced by one's personal accomplishments and goal attainment (Bandura, 1986; Lent et al., 2002). While the experience of success increases self-efficacy, repeated failures tend to decrease it (Lent et al., 2002).

The role of self-efficacy in academic and career success has been 
underscored in the literature. Among college students, self-efficacy has been found to be associated with greater persistence and academic success (Wright, Jenkins-Guarnieri, \& Murdock, 2013). Academic self-efficacy was correlated with effort regulation, deep processing strategies, and mastery goal orientation, which contribute to better academic performance (Honicke \& Broadbent, 2016). Further, students with greater self-efficacy were more likely to practice selfregulation and show persistence in the face of difficulties (Komarraju \& Nadler, 2013). Career self-efficacy was found to be a determinant of self-determined motivation and satisfaction with one's course and academic major among college students (Komarraju, Swanson, \& Nadler, 2014); and career decision self-efficacy was associated to career adaptability (Hou, Wu, \& Liu, 2014).

As the educational system increasingly recognizes the importance of career and talent development, which entails helping students strengthen and maximize specific skills necessary for working in a particular field, the self-efficacy of students in this area has recently gained attention. This led to the conceptualization of domain-specific career and talent development self-efficacy (Yuen, Gysbers, Chan, Lau, \& Shea, 2010). Career and talent development self-efficacy enables the development of autonomous lifelong learners capable of fulfilling their potentials, enhancing their quality of life, and making positive contributions to the society (Yuen et al., 2010).

Career and talent development self-efficacy has three components. This includes the confidence in applying life skills that are crucial in (1) developing one's talents (talent development); (2) acquiring and applying positive work habits (work habits and values); and (3) exploring career possibilities (career exploration) (Yuen et al., 2010). Career and talent development self-efficacy was found to be associated with academic performance and career decision self-efficacy (Fan, Hao, \& Yuen, 2013; Yuen et al., 2010). Among Filipino university students, career and talent development self-efficacy, specifically the talent development and career exploration self-efficacy domains, has been revealed to be predicted by the triarchic model of grit composed of consistency of interests, perseverance of effort, and adaptability to situations (Datu, Yuen, \& Chen, 2017).

In order to understand the factors that contribute to one's career 
and talent development self-efficacy, we utilize the engine model of well-being (Jayawickreme, Forgeard, \& Seligman, 2012). The model posits that well-being variables can be distinguished into: (1) inputs, or resources that enable well-being; (2) processes, or internal states of mechanisms that influence well-being; and (3) outcomes, or valuable behaviors that characterize the attainment of well-being. In line with the engine model of well-being, we propose self-compassion as an endogenous/personality input variable that predicts well-being. Because hope involves cognitions regarding pathways and agencies in the achievement of one's goals, and could be influential in the choices one makes in the attainment of well-being, we identify hope as a process variable. Although career and talent development selfefficacy, being an enabling resource, may also be viewed as a process variable in the attainment of well-being in the engine model, we contend that compared to self-compassion and hope, career and talent development self-efficacy is more domain-specific, and thus, a more proximal determinant of the desired outcome behaviors that represent well-being in the context of present study, such as developing one's talents, acquiring and applying positive work habits, and exploring career possibilities. Indeed, cognitions pertaining to one's capabilities (i.e., self-efficacy) are the most important determinants of behaviors one chooses to engage in (Maddux, 2002). The following sections present a review of literature that supports a model of career and talent development self-efficacy predicted by self-compassion through hope.

\section{Self-compassion and Career and Talent Development Self- Efficacy}

Self-compassion refers to being kind and understanding toward oneself, especially in times of failure and difficulty. It has three basic components: (1) being kind and understanding rather than harshly critical and judgmental toward oneself (self-kindness versus selfjudgment); (2) viewing one's experiences as being connected to rather than being detached from a larger human experience (common humanity versus isolation); and (3) having a balanced awareness of rather than over-identifying with one's painful thoughts and feelings (mindfulness versus over-identification) (Neff, 2003). Self- 
compassion is associated with indicators of psychological functioning such as happiness, positive affect, personal initiative, and curiosity and exploration beyond that attributable to personality, and is thus considered a positive psychological construct (Neff, Rude, \& Kirkpatrick, 2007).

The adaptive role of self-compassion has been demonstrated in previous studies. Among college students, increased self-compassion has been found to be related to mindfulness, optimism, and self-efficacy, as well as a decrease in rumination (Smeets, Neff, Alberts, \& Peters, 2014). Protective functions of self-compassion against the negative effects of self-doubt (Marshall et al., 2015), academic burnout, and depression (Kyeong, 2013) have also been found. Students with higher self-compassion were more successful in dealing with difficulties, homesickness, and depression, and were more satisfied with their decision to pursue higher education in the university (Terry, Leary, \& Mehta, 2013). They were less affected by the negative emotional consequences of thwarted goal progress; and in the long run, selfcompassion was found to be linked to greater life satisfaction, identity development, and decrease in negative affectivity (Hope, Koestner, \& Milyavskaya, 2014). The protective role of self-compassion against symptoms of anxiety, depression, and stress has also been reported (Muris, Meesters, Pierik, \& de Kock, 2016; Pinto-Gouveia, Duarte, Matos, \& Fráguas, 2014).

Compared to individuals with low self-compassion, highly selfcompassionate ones are less likely to react negatively toward failure. Instead of amplifying their inadequacies with harsh self-judgments, they tend to take a more balanced perspective, which leads them to view their abilities more positively and perceive themselves as more competent (Neff, Hsieh, \& Dejitterat, 2005). In addition, instead of attributing failure solely to oneself, individuals with high selfcompassion are likely to acknowledge that failure is something that is present as well in the lives of others, and thus, treat themselves with more kindness despite the experience of failure (de Souza \& Hutz, 2016). Thus, self-compassion could be instrumental in the increase of self-efficacy. The positive relationship of self-compassion with self-efficacy has been reported in literature (de Souza \& Hutz, 2016; Iskender, 2009). 
The association of self-compassion with self-efficacy supports the notion that students with higher self-compassion would view themselves as more capable of developing specific skills required to work in a particular career field, acquiring and applying positive work habits and values, and exploring career possibilities. In line with this, we propose that self-compassion would positively predict the domainspecific career and talent development self-efficacy. Moreover, we also postulate that this relationship would be mediated by hope.

\section{Hope as Mediator}

Hope is a positive psychological construct that pertains to one's perceived capability to attain important life goals. It involves cognitions regarding finding ways to achieve one's goals (i.e., pathways thinking) and the motivation to use these ways to reach the desired goals (i.e., agency thinking) (Snyder, 2002). This conceptualization of hope was soon expanded to include not only internal agents, but also external agents like one's family, peers, and spiritual/supernatural beings as well (Bernardo, 2010). More recently, a more integrative conceptualization of hope as a future-oriented expectation of attaining personally valued goals was suggested, which involves the dimensions of trust and confidence, positive future orientation, social relations and personal value, and the absence of lack of perspective (Schrank, Woppmann, Sibitz, \& Lauber, 2011).

Past studies have supported the role of hope in positive youth development, academic success, and career development. In a longitudinal study among adolescents, hope was found to have led to greater positive affect and well-being as they go through a period of transition (Ciarrochi, Parker, Kashdan, Heaven, \& Barkus, 2015). It was also associated with life satisfaction, optimism, and self-esteem (Yarcheski \& Mahon, 2016). Hope was found to be an important factor in academic achievement as it predicted students' number of semesters enrolled, whether they returned for another year in college, and whether they finished college on time, as well as their academic performance (Gallagher, Marques, \& Lopez, 2017). Moreover, a link between hopeful thinking and grade expectations, which predicted academic achievement, was found (Levi, Einav, Ziv, Raskind, \& 
Margalit, 2014). Fostering hope among students could also address high drop-out rates in college as it contributes to students' persistence and academic success (Wells, Gilbert, Mahle-Grisez, Newman, \& Rowell, 2014). It could also be beneficial to career development through its relationship with career decidedness, career planning, career self-efficacy beliefs, and life and job satisfaction (Hirschi, 2014).

There is evidence in literature that links self-compassion with hope. As self-compassion entails kindness to oneself, failure situations are viewed as opportunity for learning and mastery rather than responding with harsh self-criticisms (Neff et al., 2005). Being kind to oneself also involves doing things that can make one happy. Thus, selfcompassionate individuals are more likely to take on challenging tasks and learning new skills that can lead toward achieving their goals, and are also more open to changing themselves for the better as they acknowledge their weaknesses (Neff \& Dahm, 2015). The positive selfattitude and enhanced perception of competence that self-compassion promotes can facilitate the identification of desired goals, and assist in perceiving and sustaining higher motivation toward goals even in difficult situations, thereby increasing hope (Yang, Zhang, \& Kou, 2016).

Hope, in turn, is associated with increased self-efficacy. This relationship has been demonstrated in the academic (Feldman \& Kubota, 2015), career (In, 2016), and occupational (Hirschi, 2014) domains. Because hope involves envisioning various means toward achieving important goals and motivation to attain these goals, it allows individuals to reflect on their personal choices and strengths (Hirschi, Abessolo, \& Froidevaux, 2015). Moreover, hope serves a buffering role especially during stressful situations, making it an important resource for individuals to recognize and focus on their capabilities (In, 2016). The relationships of self-compassion, hope, and self-efficacy demonstrated in the literature support the idea that self-compassion could predict career and talent development selfefficacy through hope.

\section{The Present Study}

The present study intends to examine a model of career and 
talent development self-efficacy predicted by self-compassion through hope in a sample of Filipino college students. By examining factors that could possibly contribute to enabling students to develop their talents, explore career possibilities, and acquire positive work habits and values, the findings of the study could inform the role of positive education, which fosters students' strengths and well-being in addition to academic skills, in the Philippine educational setting. Moreover, by providing a better understanding of students' career and talent development self-efficacy, programs that enhance this enabling resource can be developed in order to complement the changes in the curriculum in attaining the goals of the educational reforms in the Philippines of developing lifelong learners that are highly competent in their chosen careers and capable of contributing to the society (see Figure 1) .

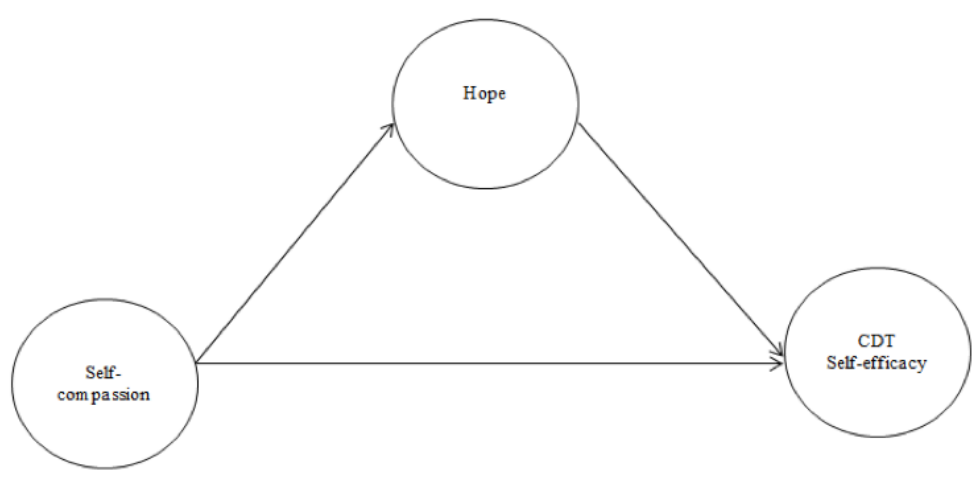

Figure 1. Proposed model of career and talent development self-efficacy predicted by self-compassion through hope. (CTD Self-efficacy = career and talent development self-efficacy) 


\section{METHOD}

\section{Participants and Procedures}

The participants of the study are 620 college students with mean age of 17.9 years old $(S D=1.9)$. The sample is composed of $60.3 \%$ ( $n$ $=374)$ males, $39.2 \%(n=243)$ females; $0.5 \%(n=3)$ did not report their sex. All the participants provided informed consent prior to the administration of the survey questionnaires. They were also informed of their rights such as that of anonymity and confidentiality. All applicable ethical standards were adhered to during the course of the study.

\section{Measures}

Career and talent development self-efficacy was measured using the Career and Talent Development Self-Efficacy Scale (CTD-SES; Yuen et al., 2010). CTD-SES has 18 items rated on a 6-point scale from 1 (extremely lacking confidence) to 6 (extremely confident). It has three subscales: talent development self-efficacy ("I am confident that I can explore my capabilities in academic subjects."), work habits and values self-efficacy ("I am confident that I can work autonomously."), and career exploration self-efficacy ("I am confident that I can explore my career path and goal."). The mean for each subscale and the grand mean for overall career and talent development self-efficacy were calculated.

Self-compassion was assessed using the Self-Compassion Scale (SCS; Neff, 2003), a 26-item scale composed of six subscales, namely: self-kindness ("I try to be understanding and patient towards those aspects of my personality I don't like."); self-judgment ("When I see aspects of myself that I don't like, I get down on myself."); common humanity ("When I feel inadequate in some way, I try to remind myself that feelings of inadequacy are shared by most people."); isolation ("When I fail at something that's important to me I tend to feel alone in my failure."); mindfulness ("When something upsets me I try to keep my emotions in balance."); and over-identification ("When something upsets me I get carried away with my feelings.”). The items were rated 
on a scale of 1 (almost never) to 5 (almost always). Self-judgment, isolation, and over-identification subscales were reverse-coded so that higher scores would represent higher levels of self-compassion. The mean of each subscale was calculated, as well as the grand mean for the overall measure of self-compassion.

Hope was measured using the Integrative Hope Scale (IHS; Schrank et al., 2011). IHS has 23 items rated from 1 (strongly disagree) to 6 (strongly agree). Its four subscales are trust and confidence ("I have deep inner strength."), lack of perspective ("It is hard for me to keep up my interest in activities I used to enjoy."), positive future orientation ("I look forward to doing things I enjoy."), and social relations and personal value ("I feel loved."). The lack of perspective subscale was reverse-coded so that higher scores would correspond to higher levels of hope. The total scores for the subscales and grand total for overall hope were calculated.

All the scales were administered in their original English forms since the participants are Filipino-English bilinguals. Based on the data from the current sample, all scales demonstrated adequate reliability. The composite reliability coefficient rho for CTD-SES, SCS, and IHS are $.93, .82$, and .90, respectively.

\section{Data Analysis}

To examine a model of career and talent development self-efficacy predicted by self-compassion through hope, mediation analysis through structural equation modeling (SEM) with test of indirect effects and using maximum likelihood estimator was utilized. Latent self-compassion (indicators: self-kindness, self-judgment, common humanity, isolation, mindfulness, and over-identification) was entered as the independent variable; latent hope (indicators: trust and confidence, lack of perspective, positive future orientation, and social relations and personal value) as mediator; and latent career and talent development self-efficacy (indicators: career exploration, talent development, and work habits and values) as outcome variable. The model was evaluated based on the following fit indices: chi-square $\left(\chi^{2}\right)$, comparative fit index (CFI), Tucker-Lewis index (TLI), and root mean square error of approximation (RMSEA). Conventional cutoff values 
were used: CFI and TLI values of $>.90$ were regarded as acceptable fit and $>.95$ as good fit. RMSEA value of $<.08$ was interpreted as acceptable fit and $<.06$ as good fit (Beauducel \& Wittmann, 2005).

\section{RESULTS}

Since CTD-SES is a relatively new scale, we examined its factor structure using confirmatory factor analysis (CFA). The three-factor with one higher-order factor model of career and talent development self-efficacy has the following fit indices: $\chi^{2}=465.47(d f=132, p<.01)$, $\chi^{2} / d f=3.53, \mathrm{CFI}=.91$, TLI $=.90$, and RMSEA $=.06(90 \% \mathrm{CI}=.06$ to .07), indicating acceptable fit to the data from the current sample. This supports the validity of the scale among Filipino college students.

The means, standard deviations, and correlations of the study variables are shown in Table 1. Prior to SEM, the measurement models of self-compassion and hope were also evaluated. CFA of the measurement model of self-compassion yielded the following fit indices: $\chi^{2}=32.48(d f=9, p<.01), \chi^{2} / d f=3.61, \mathrm{CFI}=.98$, TLI $=.96$, and RMSEA $=.06$ ( $90 \% \mathrm{CI}=.03$ to .08 ); while the following are the fit indices for the measurement model of hope: $\chi^{2}=6.46(d f=2, p<.05)$, $\chi^{2} / d f=3.23, \mathrm{CFI}=.99, \mathrm{TLI}=.97$, and RMSEA $=.06(90 \% \mathrm{CI}=.01$ to .12). Both demonstrated good fit.

SEM for the model wherein career and talent development selfefficacy is predicted by self-compassion through hope resulted to the following fit indices: $\chi^{2}=134.85(d f=62, p<.01), \chi^{2} / d f=2.18, \mathrm{CFI}=$ .98 , TLI $=.98$, and RMSEA $=.04(90 \% \mathrm{CI}=.03$ to .05$)$. This shows that the model has good fit to the data in a sample of Filipino college students. The path between self-compassion and hope, and that between hope and career and talent development self-efficacy were found to be significant. The direct effect between self-compassion and career and talent development self-efficacy was not significant (direct effect $=.12$, S.E. $=.08, p>.05$ ), while the indirect effect through hope was significant (indirect effect $=.43$, S.E. $=.09, p<.01$ ). Thus, hope significantly mediated the relationship between self-compassion and career and talent development self-efficacy. Figure 2 shows the model with standardized parameter estimates.

Because the study made of use cross-sectional data, inferences 


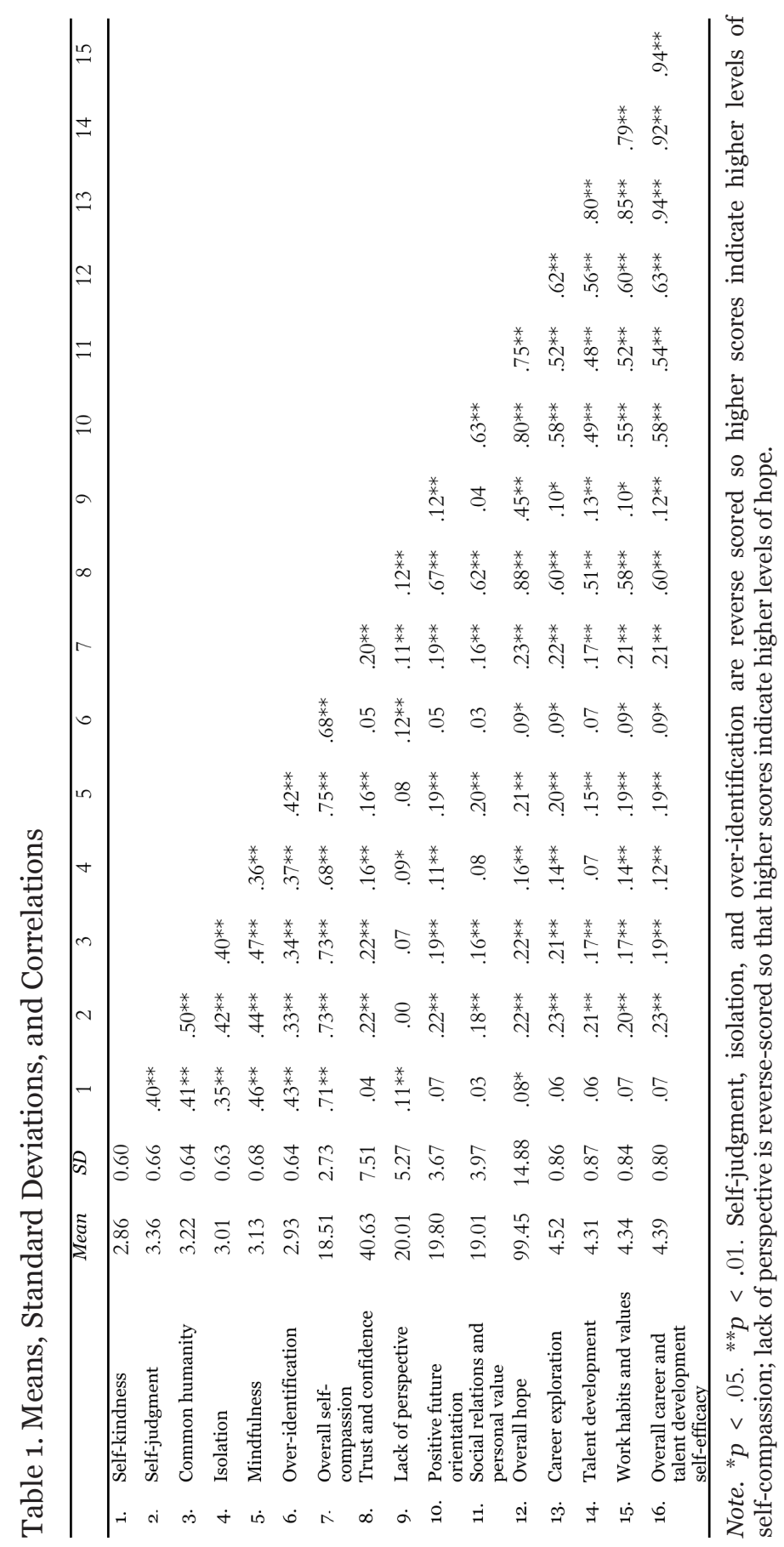




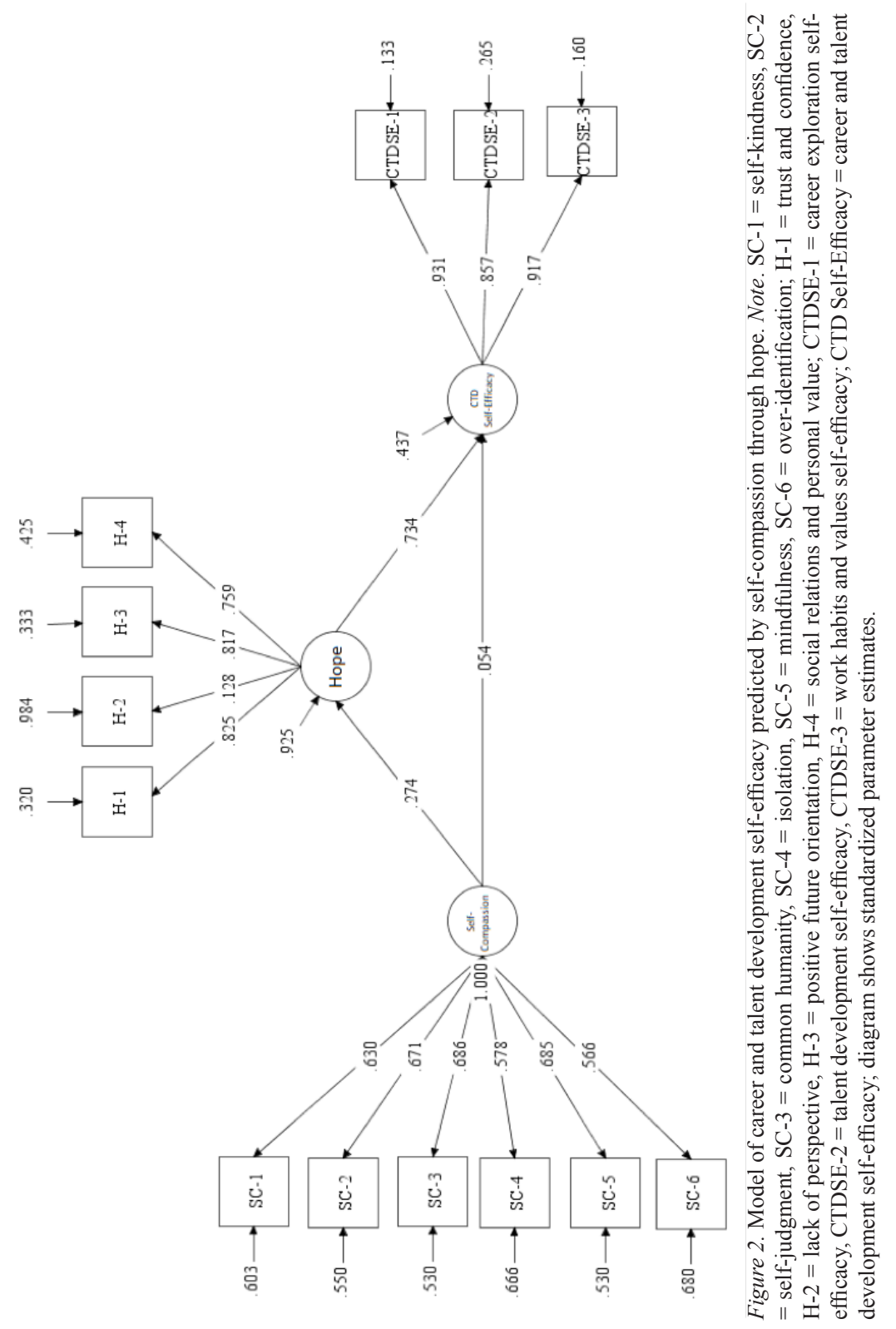


regarding temporal relationships and causation among variables cannot be made. Nevertheless, to provide support for the specificity of the mediation model, we tested an alternative model wherein career and talent development self-efficacy is predicted by hope through selfcompassion. While the alternative model demonstrated good fit to the data $\left(\chi^{2}=134.85[d f=62, p<.01], \chi^{2} / d f=2.18, \mathrm{CFI}=.98\right.$, TLI $=.96$, and RMSEA $=.04$ [90\% CI $=.03$ to .05]) and significant direct effect of hope on self-efficacy was found (direct effect $=.10$, S.E. $=.01, p<$ $.01)$, the indirect effect through self-compassion was not significant (indirect effect $=.002$, S.E. $=.001, p>.05$ ). Thus, the model where self-compassion is the mediator was not supported.

\section{DISCUSSION}

The study examined a model of career and talent development self-efficacy predicted by self-compassion through hope in a sample of Filipino college students. Results of SEM revealed that the model has good fit to the data. There was no significant direct effect between selfcompassion and career and talent development self-efficacy, while the indirect effect of self-compassion on career and talent development self-efficacy through hope was significant. This means that students who exhibit kindness and understanding toward themselves, especially during failures and difficult situations, are more likely to have a positive outlook in terms of attaining the goals they personally value. Having positive expectations of achieving one's goals, in turn, is associated with students' more positive perceptions about their ability to develop their talents, acquire and practice positive work values and habits, and explore career opportunities.

The results can be interpreted in light of the engine model of well-being (Jayawickreme et al., 2012). As an input variable, selfcompassion serves as an endogenous resource that contributes to one's well-being by allowing an individual to remain kind and understanding of one's self despite the experience of failure. It is to be noted that goal attainment and experiences of failure and success are crucial to one's self-efficacy, which is an important determinant of outcome behaviors that reflect well-being (Lent et al., 2002; Maddux, 2002). While failure can be deleterious to one's self-efficacy, being self- 
compassionate serves a protective role by allowing one to have a more balanced perspective toward failure by viewing it as a common human experience and avoiding harsh self-criticisms rather than viewing it as a reflection of one's lack of competence (de Souza \& Hutz, 2016; Neff et al., 2005). Self-compassion helps one to see the challenging situation as a learning experience and an opportunity to improve oneself (Neff et al., 2005). This encourages the individual to take on challenging activities, learn new skills, and engage in self-betterment (Neff \& Dahm, 2015). These activities can facilitate in the identification of goals and motivate one to pursue these goals despite difficulties as one's hope increases (Yang et al., 2016).

As a process variable, being hopeful entails a recognition of one's strengths and personal and social resources, as well as looking forward to and planning for the future (Schrank et al., 2011). It enhances individuals' consciousness of their abilities and skills (Hirschi et al., 2015), thereby allowing them to have more positive perceptions regarding their capability to achieve their desired goals, which characterize greater self-efficacy. When viewed from the perspective of career and talent development in the educational setting, self-efficacy can manifest in the students' confidence in performing outcome behaviors reflective of well-being, such as developing skills required for their chosen fields of career, acquiring and applying positive work habits and values, and exploring career possibilities (Yuen et al., 2010).

The findings of the study have important implications. Theoretically, the validation of a model of career and talent development self-efficacy predicted by self-compassion through hope allows for a better understanding of factors that could possibly contribute to the development of students' enabling resources that would allow them to maximize their skills and abilities in order to develop their talents and prepare them for their chosen field of career. With the engine model of well-being as a framework, the findings support the mechanism as to how the endogenous trait of being self-compassionate is associated with perceptions of one's capability of performing outcome behaviors that reflect well-being (i.e., career and talent development self-efficacy) through the process of increasing an individual's positive cognitions regarding pathways and agencies in the attainment of one's goals (i.e., hope). 
In terms of practical implications, the findings support the contention that students' career and talent development self-efficacy can be developed through interventions targeted toward increasing their self-compassion and hope. The non-significant direct effect of self-compassion on career and talent development self-efficacy, and the significant indirect effect through hope indicate that such interventions can initially aim to increase hope by enhancing students' self-compassion. The increased hope, in turn, can be directed toward developing their career and talent development self-efficacy.

The information gained in the study could be beneficial for guidance counselors in the development of programs for senior high school and college students that promote enablement in their career and talent development by increasing their self-efficacy in this domain. This could complement the changes in the curriculum enacted by the recent reforms in the Philippine education toward developing lifelong learners that are competent and capable in contributing to the society. Further, in support to the idea of positive education, the study highlights the importance of integrating positive psychological approaches that enhance students' strengths and personal resources, such as self-compassion, hope, and career and talent development self-efficacy, to traditional education in order to allow a more holistic development of Filipino learners.

We acknowledge that the study has some limitations. First, the use of self-report measures in the assessment of the study variables has inherent weaknesses such as being prone to social desirability and other forms of biases. Second, since the study used crosssectional method in data gathering, causation cannot be inferred. An experimental or longitudinal study may be warranted in order to establish the temporal relationships of the variables. Third, while the engine model of self-efficacy (Jayawickreme et al., 2012) defined output variables as behaviors reflective of well-being, we only measured the students' perceptions of their capability in performing such behaviors (i.e., career and talent development self-efficacy). This study can be expanded in the future by looking into the participants' actual skills and abilities to develop their talents, practice positive work values and habits, and explore career opportunities. Lastly, considering the context of the Philippine educational system, the findings of the 
study might be applicable only to Filipino learners and might not be generalizable to other populations. Nonetheless, the study provides a better understanding of career and talent development self-efficacy, which is an important enabling resource that could allow students to maximize their skills and abilities in developing their talents and the attainment of their career goals.

\section{REFERENCES}

Bandura, A. (1986). Social foundations of thought and action: A social cognitive theory. Englewood Cliffs, NJ: Prentice Hall.

Beauducel, A., \& Wittmann, W. W. (2005). Simulation study on fit indexes in CFA based on data with slightly distorted simple structure. Structural Equation Modeling, 12(1), 41-75.

Bernardo, A. B. (2010). Extending hope theory: Internal and external locus of trait hope. Personality and Individual Differences, 49(8), 944-949.

Ciarrochi, J., Parker, P., Kashdan, T. B., Heaven, P. C., \& Barkus, E. (2015). Hope and emotional well-being: A six-year study to distinguish antecedents, correlates, and consequences. The Journal of Positive Psychology, 10(6), 520-532.

Datu, J. A. D., Yuen, M., \& Chen, G. (2017). Development and validation of the Triarchic Model of Grit Scale (TMGS): Evidence from Filipino undergraduate students. Personality and Individual Differences, 114, 198-205.

de Souza, L. K. D., \& Hutz, C. S. (2016). Self-compassion in relation to self-esteem, self-efficacy and demographical aspects. Paidéia (Ribeirão Preto), 26(64), 181-188.

Fan, W., Hao, D., \& Yuen, M. (2013). Psychometric properties of the Career and Talent Development Self-Efficacy Scale when used with Chinese university students. Asian Journal of Counselling, 2O(1), 59-84.

Feldman, D. B., \& Kubota, M. (2015). Hope, self-efficacy, optimism, and academic achievement: Distinguishing constructs and levels of specificity in predicting college grade-point average. Learning and Individual Differences, 37, 210-216. 
Gallagher, M. W., Marques, S. C., \& Lopez, S. J. (2017). Hope and the academic trajectory of college students. Journal of Happiness Studies, 18(2), 341-352.

Hirschi, A. (2014). Hope as a resource for self-directed career management: Investigating mediating effects on proactive career behaviors and life and job satisfaction. Journal of Happiness Studies, 15(6), 1495-1512.

Hirschi, A., Abessolo, M., \& Froidevaux, A. (2015). Hope as a resource for career exploration: Examining incremental and cross-lagged effects. Journal of Vocational Behavior, 86, 38-47.

Honicke, T., \& Broadbent, J. (2016). The influence of academic self-efficacy on academic performance: A systematic review. Educational Research Review, 17, 63-84.

Hope, N., Koestner, R., \& Milyavskaya, M. (2014). The role of selfcompassion in goal pursuit and well-being among university freshmen. Self and Identity, 13(5), 579-593.

Hou, C., Wu, L., \& Liu, Z. (2014). Effect of proactive personality and decision-making self-efficacy on career adaptability among Chinese graduates. Social Behavior and Personality: An International Journal, 42(6), 903-912.

In, H. (2016). Acculturation and hope as predictors of career decision self-efficacy among Korean international undergraduate students. Journal of Career Development, 43(6), 526-540.

Iskender, M. (2009). The relationship between self-compassion, selfefficacy, and control belief about learning in Turkish university students. Social Behavior and Personality: An International Journal, 37(5), 711-720.

Jayawickreme, E., Forgeard, M. J., \& Seligman, M. E. (2012). The engine of well-being. Review of General Psychology, 16(4), 327342.

Komarraju, M., \& Nadler, D. (2013). Self-efficacy and academic achievement: Why do implicit beliefs, goals, and effort regulation matter? Learning and Individual Differences, 25, 67-72.

Komarraju, M., Swanson, J., \& Nadler, D. (2014). Increased career self-efficacy predicts college students' motivation, and course and major satisfaction. Journal of Career Assessment, 22(3), 420432. 
Kyeong, L. W. (2013). Self-compassion as a moderator of the relationship between academic burn-out and psychological health in Korean cyber university students. Personality and Individual Differences, 54(8), 899-902.

Lent, R. W., Brown, S. D., \& Hackett, G. (2002). Social cognitive career theory. In D. Brown (Eds.), Career choice and development (4th ed., pp. 255-311). NY: Jossey-Bass, John Wiley \& Sons, Inc.

Levi, U., Einav, M., Ziv, O., Raskind, I., \& Margalit, M. (2014). Academic expectations and actual achievements: The roles of hope and effort. European Journal of Psychology of Education, 29(3), 367386.

Maddux, J. E. (2002). Self-efficacy: The power of believing you. In C. R. Snyder \& S. J. Lopez (Eds.), Handbook of positive psychology (pp. 277-287). NY: Oxford University Press.

Marshall, S. L., Parker, P. D., Ciarrochi, J., Sahdra, B., Jackson, C. J., \& Heaven, P. C. (2015). Self-compassion protects against the negative effects of low self-esteem: A longitudinal study in a large adolescent sample. Personality and Individual Differences, 74, 116-121.

Muris, P., Meesters, C., Pierik, A., \& de Kock, B. (2016). Good for the self: Self-compassion and other self-related constructs in relation to symptoms of anxiety and depression in non-clinical youths. Journal of Child and Family Studies, 25(2), 607-617.

Neff, K. D. (2003). The development and validation of a scale to measure self-compassion. Self and Identity, 2(3), 223-250.

Neff, K. D., \& Dahm, K. A. (2015). Self-compassion: What it is, what it does, and how it relates to mindfulness. In B. D. Ostafin, M. D. Robinson, \& B. P. Meier (Eds.), Handbook of mindfulness and self-regulation (pp. 121-137). New York: Springer.

Neff, K. D., Hsieh, Y. P., \& Dejitterat, K. (2005). Self-compassion, achievement goals, and coping with academic failure. Self and Identity, 4(3), 263-287.

Neff, K. D., Rude, S. S., \& Kirkpatrick, K. L. (2007). An examination of self-compassion in relation to positive psychological functioning and personality traits. Journal of Research in Personality, 41(4), 908-916.

Norris, J. M., Williams, P., O’Connor, M., \& Robinson, J. (2013). An 
applied framework for positive education. International Journal of Wellbeing, 3(2), 147-161.

Pinto-Gouveia, J., Duarte, C., Matos, M., \& Fráguas, S. (2014). The protective role of self-compassion in relation to psychopathology symptoms and quality of life in chronic and in cancer patients. Clinical Psychology \& Psychotherapy, 21(4), 311-323.

Schrank, B., Woppmann, A., Sibitz, I., \& Lauber, C. (2011). Development and validation of an integrative scale to assess hope. Health Expectations, 14(4), 417-428.

Seligman, M. (2011). Flourish. London: Nicholas Brealey Publishing.

Smeets, E., Neff, K., Alberts, H., \& Peters, M. (2014). Meeting suffering with kindness: Effects of a brief self-compassion intervention for female college students. Journal of Clinical Psychology, 7o(9), 794-807.

Snyder, C. R. (2002). Hope theory: Rainbows in the mind. Psychological Inquiry, 13(4), 249-275.

Terry, M. L., Leary, M. R., \& Mehta, S. (2013). Self-compassion as a buffer against homesickness, depression, and dissatisfaction in the transition to college. Self and Identity, 12(3), 278-290.

Wells, M., Gilbert, E., Mahle-Grisez, L., Newman, R., \& Rowell, K. (2014). High hopes: Fostering a culture of hope at a community college. Mid-Western Educational Researcher, 26(1), 60-66.

Wright, S. L., Jenkins-Guarnieri, M. A., \& Murdock, J. L. (2013). Career development among first-year college students: College self-efficacy, student persistence, and academic success. Journal of Career Development, 40(4), 292-310.

Yang, Y., Zhang, M., \& Kou, Y. (2016). Self-compassion and life satisfaction: The mediating role of hope. Personality and Individual Differences, 98, 91-95.

Yarcheski, A., \& Mahon, N. E. (2016). Meta-analyses of predictors of hope in adolescents. Western Journal of Nursing Research, 38(3), 345-368.

Yuen, M., Gysbers, N. C., Chan, R. M., Lau, P. S., \& Shea, P. M. (2010). Talent development, work habits, and career exploration of Chinese middle-school adolescents: Development of the career and talent development self-efficacy scale. High Ability Studies, 21(1), 47-62. 